\title{
A Framework of Efficient Material Storage Management on Congested Construction Site
}

\author{
Nurul Fathira Misron ${ }^{1,2}$, Muhamad Azry Khoiry ${ }^{1,2^{*}}$, Noraini Hamzah ${ }^{1,2}$ \\ ${ }^{1}$ Programme of Civil Engineering, Faculty of Engineering \& Built Environment, Universiti \\ Kebangsaan Malaysia, 43650 Bangi, Malaysia \\ ${ }^{2}$ Smart and Sustainable Township Research Centre (SUTRA), Faculty of Engineering \& Built \\ Environment, Universiti Kebangsaan Malaysia, 43650 Bangi, Malaysia
}

\begin{abstract}
Material storage management focuses on starting material into the built-up site to be recorded, the material layout and stored over a certain period until it is taken out of the storage area to the work site and the process is repeated. The emergence of new technologies that are not integrated and have no efficient management methods as well as inexperienced management negatively affect the storage management of overcrowded site sites. This study aims to devise an efficient set of materials storage management on a congested site. Critical studies have been referred on more than 50 previous research journals covering by the elements. The framework of this study comprises four elements that are defined as workflow of storage management, storage management systems, material storage methods and roles of responsible parties. The combination of the elements can contribute to the strengthening or discovery of the theory or concept that can be used by the developmental growth and future of the industry.
\end{abstract}

\section{Introduction}

The management of a construction requires integrated processes to ensure that the work can be completed on time, cost and meet specified contract specifications [1]. This is because management that related to materials is very important from the design stage to the construction stage [2]. The management of building materials is generally recognized as an integrated coordination of material removal, purchase, delivery, receiving of materials on site, warehousing or storage and installation [3]. However, all process of early planning cannot be performed properly without a controlled or coordinated technique or system. An important component of construction management is the construction industry where the parties need to understand the appropriate material management techniques and their effectiveness on the implementation of construction projects [4].

This management is the strategies to ensure the outflow and entry of each building material in order to improve the organization of the construction area as well as to control the flow of construction materials from the storage area to the construction site [5]. Additionally, a good planning and control system ensures the quality and quantity of a

* Corresponding author: azrykhoiry@ukm.edu.my 
building material is accurate and timely [6]. Good management is carried out to resolve potential problems such as material shortages, materials supply delays, non-schedule, material damage and wastage and lack of storage space [2]. While the issues often raised are related to congested site moreover in limited urban areas and site plans are reserved. The underlying aspects of the site also take into several issues such as lack of adequate storage space, less room for effective handling of materials, accidents due to poor management and less adequate space to for remaining building materials [7]. Subsequently, an increase of congested sites in the construction industry is a global scale in urban development research also shows that regeneration areas are more prominent than urban resettlement areas [8]. The improvement of industry is urban development and it demonstrates an efficient need for material space, equipment and workforce but the environment needs to be limited. The construction often involves a large number of activities that work simultaneously to share construction space and may require the same area or space on the same time [9].

There are four categories workflow of material storage management namely planning and arrangement, implementation and handling, control and monitoring and supervision. Planning matters involving the determination of material requirements for carrying out production and other related work processes such as determining the types of materials to be used in construction works, quantities, and specifications to carry out construction work [10]. Material managers should play a role in determining storage locations, layouts and all necessary equipment including coding and cataloging, material acceptance, material inspection, building materials storage safety, material production, cost data preparation, stock records and disposing of bad building materials or cannot be used [11]. Appropriate storage facilities should be provided for the on-site materials, some materials usually not stored in material storage and additional material handling are to avoid wastage [12]. In addition, observe the materials sent to the storage area and always refer to the storage of materials to detect quantities and to avoid theft cases and so on [13].

Material layout planning is part of material management in construction projects and it is includes layout and compilation of materials and storage facilities and storage plan development [14]. Many studies have been conducted to optimize site layout plans or logistics plans separately, the conflicts are contradictory and the results of layout plans and logistics planners are neglected in construction planning and design phase [15]. The use of new equipment and innovative material handling methods has influenced changes in construction technology in recent years where this method has been supported by suppliers across various industrial sectors outside construction [16]. Additionally, improved material related to management using modern technologies available today such as mobile phones and laptops or other appropriate and affordable technologies such as the internet, RFID (Radio Frequency Identification), GIS (GPS Information System), GPS (Global Positioning System), tracking technologies available should be used to assist in better material handling as well as the ability to detect materials [17].

However, the role of responsible parties is important in mobilizing this work process. In addition to training and education what workers need to know before moving, handling and storing building materials is to know the general principles of safety such as proper work practices, tools, and controls that can help reduce accidents at work and they need to understand the potential hazards that related to the task and how to control it whether the material moves manually or mechanically [18]. The general factor that causes building defects is the low quality of materials where it is important to the relevant parties in the construction to ensure good and acceptable use of the material throughout the project to ensure a satisfactory end product of the product and conform to specifications [19]. 


\section{Methodology}

The literature review carried out in this study is extensively highlighted in terms of the efficient management of materials at the site of congested construction site. Selection of the title is made after several discussions and looks at the context of storage of material storage. Paper has been identified through structured keyword search and functionality in major databases and legitimate publishing websites (Elsevier ScienceDirect, Wiley InterScience, SCOPUS, SpringerLink, Jstor, Emerald Insight, Ebsco). The keywords are "building materials", "crowded sites", "storage" combined with those related to management is "material management", "material storage management", "space". Methods of the study method are as outlined in Figure 1.

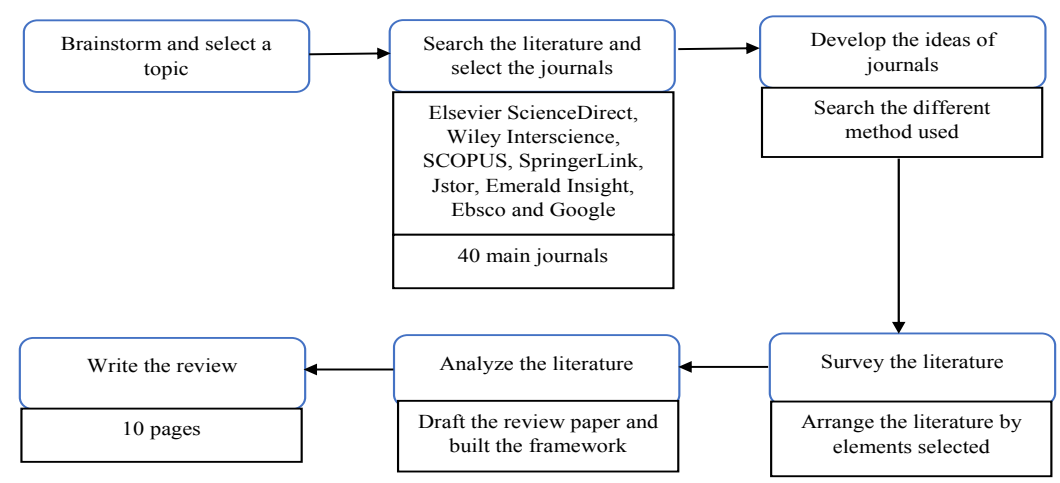

Fig. 1. Research process

Steps to develop the idea of past research in which to make the selection and comparison of systems or concepts can be matched with the goal of this study and then discussed in detail the process of producing a framework of efficient material storage management at overcrowded site that categorized into four elements. Furthermore, the paper has been set up with a research method available in four categories: modeling, theoretical studies, case studies and literature studies. In addition, material collection has been described by way of search and for analysis, a set of frameworks has been developed to explain the elements contained.

\section{Analysis of the papers and discussion}

The framework has been discussed based on critical studies through previous research that having four essential elements - workflow of material storage management, storage management systems, materials storage methods and roles of responsible parties. The related papers where divided into the elements as shown in Figure 1. 
Table 1. Grouping papers according to element contents

\begin{tabular}{ll}
\hline \multicolumn{1}{c}{ Elements } & \multicolumn{1}{c}{ Related papers } \\
\hline 1) Workflow of material storage management & {$[5],[7],[10],[11],[13],[20-$} \\
24] & \\
2) System of storage management & {$[16],[25-37],[38-43]$} \\
3) Material storage method & {$[44-49],[50],[51]$} \\
4) The Role of Responsibility Parties & {$[4],[5],[8],[11],[12],[23]$,} \\
\hline 15$],[16],[52],[53]$ &
\end{tabular}

\subsection{Workflow of materials storage management}

Workflow of materials storage management is the criteria of management work forms that are replicated in a process. There are four workflows which are planning and arrangement, implementation and handling, controlling and, supervision and monitoring.

\subsubsection{Planning and arrangement}

Reducing material storage need more space for other tasks requiring additional space considerations. Accurate planning of tasks can help manage the efficient construction site layouts that can provide easy access and travel of materials in construction sites where proper management during storage is often neglected and this can cause poor material quality or material deterioration [20]. The material storage area must be located between outside area and the work area [7].

Management is the planning system of efforts to ensure the correct quality and quantity of materials are timely determined and the manner of obtaining at a reasonable cost [21]. Types of material storage exist either inside or outside if the internal storage is selected for the material, the decision of storage priority variable is considered to provide the internal building space to the material transmission, as described in the Logistic Analysis Model [22].

\subsubsection{Implementation and handling}

Material storage arrangements are not limited to spaces and general arrangements, but detailed tables and all conflicts, work practices and the required time must be pointed. Material handling provides the movement to ensure the material is in the systematic state required in designing the system where the frequency of handling material is a consideration of quality [23]. Furthermore, the reporting facilities on work progress, the materials used and required have the potential to advise the management of the materials required, when and where they are required to follow the instructions, deliver and store the arrangements to be carried out [24].

\subsubsection{Controlling}

Proper control of material storage by the workers can result in high productivity in a construction. Among the key responsibilities of the responsible party as well as controlling the outflow of materials is to control the materials storage planning, managing information or issues by weekly and monthly meetings, assisting in making and determining the required building materials demand and suitability of storage areas, assist in the coordination of the use of building materials, meet material suppliers that meet daily, assess 
the change of material supply plan and storage schedule [5]. The changes should be made according to the appropriate size, arranging the construction materials to be reused or the second use and managing the waste of building materials.

Inventory control is the way to use the right quality and quantity material and is available when needed, besides it can also determine stock of material storage. In comparison, material shortages may cause product interruption for sale, relationships with customers are impaired, while machines and equipment are not used [11]. Therefore, it involves careful handling of stocks and maintains proper control over it.

\subsubsection{Supervision and monitoring}

Identify the needs of building materials, especially materials that have high demand so that preliminary action can be taken. In addition, observe the materials that enter to the storage and always refer to the record of material storage so that can detect quantities and to avoid theft cases and so on. [13]. Table 2 are shown the related previous research to workflow of storage management.

Table 2. The previous research related to the workflow of storage management

\begin{tabular}{|c|c|c|c|c|c|c|c|c|c|c|c|c|}
\hline & 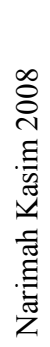 & 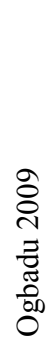 & 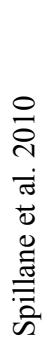 & 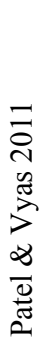 & 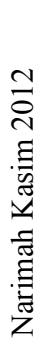 & $\begin{array}{l}\stackrel{8}{0} \\
\text { J } \\
\frac{0}{0} \\
0 \\
0 \\
0 \\
0\end{array}$ & 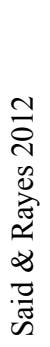 & 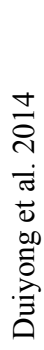 & 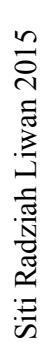 & 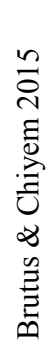 & 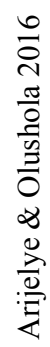 & 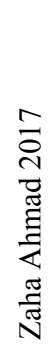 \\
\hline Planning and Arrangement & 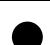 & & & & & & O & & & & & \\
\hline $\begin{array}{l}\text { Implementation and } \\
\text { Handling }\end{array}$ & & & & & & & & & & & & \\
\hline Controlling & & & & & & & & & & & & \\
\hline Supervision and Monitoring & & & & & & & & & & & & \\
\hline
\end{tabular}

\subsection{System of storage management}

There are several methods of materials storage used in industry and there are constantly reviewing the effectiveness of a construction in order to achieve the targeted quality. The use of new equipment and innovative material handling methods has influenced changes in construction technology in recent years where this method has been supported by suppliers across various industrial sectors outside construction [16].

\subsubsection{Radio Frequency Identification Technology (RFID)}

In another study, categorizing the system consists of object storage, object shelves, RFID readers and RFID tags where the RFID reader is in a fixed position and traces the tag data 
to get the coordinate of the stored object then obtains information on how the object is oriented and the information is useful to smart storage system [25-26]. The situation discussed in the study is in the storage area of the material where the remote RFID detector will be installed to obtain the material information in the attached RFID tag on the material and when the new material arrives in the area, the sensor reads the tag and automatically updates the inventory database [27].

\subsubsection{Barcode}

Bar coding technology has been used in material tracking to provide the latest and up-todate information on the quantity of substitutes and equipment exchanged between store managers and working groups [28]. Using the barcode system to detect items involving printing and attaching labels to the items, scanning labels, entering recent information into computers, and using software to track and run reports on inventory where in the middle of each barcode system is a unique identification number (ID) assigned to each detected item and ID number (in the form of barcode labels) are attached to each item in inventory [29].

\subsubsection{D/4D model technology}

Site-based simulation of site equipment that consider the layout-related actions during construction phase where planning is provided with a procedure based on a normal $3 \mathrm{D}$ model plan is equipment that automatically generated by inheritance of the information from the object [30]. This study also states that the current layout can be verified in terms of efficient working surface use, such as storage areas or transport routes by designing equipment in a simulated environment rather than using $3 \mathrm{D}-\mathrm{CAD}$, it is possible to conduct accurate material flow analysis and because of attributes selected can change over the time, objects will adaptation by autonomous to different phase of flow materials [30].

The latest development of 3D-dimensional reality technology (3D) is a laser scan and photo modeling where laser scanning allows accurate measurement of the work site and its representation in 3D format [31]. Scanning equipment sends a pulse to the object and measures the return of the signal so that the location and distance of the object can be measured. Additionally, summarizes the approaches for analysis of time-lapse conflicts in 4D and the type of established construction work space and classify spatial conflicts during construction [32]. Introducing a four-dimensional model (4D) linking the three-dimensional geometric model with construction schedule data, the visual relationship between the schedule and the construction site conditions that can facilitate results in both planning and construction stages [33].

\subsubsection{GIS (Geographic Information System)}

Studies have suggested that the Geographical Information System (GIS) which it uses to represent integrated information and systems in which a computerized approach to planning vehicle access routes on industrial sites [34]. The geographical information system (GIS) is one of the fastest growing computer-based technologies in the past two decades, but the full potential of this technology is not yet possible [35]. According to him based on GIS capability, the layout of the construction site is one of the areas that GIS can use which is a temporary facility layout. GIS is a computer-based system for collecting, storing, integrating, manipulating, analyzing, and displaying data in spatially-referenced environments, helping to visually analyze data and see patterns, trends and relationships that may not be reflected in tables or written forms [28]. Additionally, the use of GIS 
enables planners to look and analyze the impact of new construction on existing facilities and this approach can help in combining environmental aspects in the early phase of construction planning where the three categories of space available have been considered in this paper that space provided by site work in the field, space provided by temporary structures and spaces provided by structures to be built [36].

\subsubsection{JIT System (Just in Time)}

'Future-based Quality Management' (JIT) is a philosophy and a guiding principle that integrates basic management techniques, existing improvements and technical tools where it has significant impact on quality control, purchasing functions, and work culture as well as philosophy which includes costs, meeting delivery schedules, work assignments and skills development, supplier relationships and new product development [36]. Implementation of JIT does not require substantial capital expenditure on materials and equipment unless investment in employee training and restructuring of work processes other than he agrees that JIT aims to improve quality by eliminating material defects, reduced inventory, better quality, increased flexibility, increased productivity and reduced space requirements [37].

One of the features of the concept is emphasizing awareness, and provides guidance for identifying problems and solutions, requiring training to use multiple troubleshooting tools, improvements to new levels with every problem solved, require standardization of methods and procedures, high motivation, empowerment of employees, and open organizational culture is essential for the efficient implementation of JIT [36].

\subsubsection{Simulation system}

Performance measurement of effective work function is revocation and storage where these achievement measures differ from system to system in order to manage and control material effectively and to divide materials into management system parts to make system work more efficient [38]. Furthermore, investigate the factors that influence the betterment of construction work scheduling, identify the critical level of each factor and identify the method of improving the preparation of more effective construction work schedules [39]. The information obtained will be used to develop structural modeling for material management and it is hoped that these models will assist the construction industry, especially contractors to improve the efficiency of material management [40].

The simulations presented are reviewed as a tool to handle the construction site layout planning can be a complicated problem due to the interplay factor where the simulation technology capabilities to be a model complex processes in the construction project to optimizing site problem optimization, while the existing method cannot solve this problem perfectly in some cases [41]. The simulation model also takes aspect of complex interactions between facilities, activities and resources but simulations are the ideal tools for project site layout planning with repeat activity, tight interaction between strict activities and schedules and the limited resources. Otherwise, the simulation is not very beneficial [41].

\subsection{Material storage methods}

Several methods of materials storage that can be collected from past research where this method can help in planning a more efficient work process as well as a smooth and quality 
work. The two methods of storing the material are optimizing the layout space and optimizing the flow of the material.

\subsubsection{Optimizing layout space}

Layout space model that can involve five steps, namely grid size selection, 'Available Space' identification (AS) for storage and transport, installation area segmentation, actual calculation of travel distance and optimal selection of storage locations [42]. The layout optimization study is a tailor-made customization prediction to predict the strength of the material by using the DLO ("Discontinuity Layout Optimization") method evaluated through problem analysis and the available solutions and is ultimately used to improve the strength of the recall where the probabilistic study of material strength with an emphasis on various sampling sets, material properties, forms, numbers and standard deviation of space and/ or admission in SVE ("Statistical Volume Elements"), paving the way for a better understanding of the effective strength of the matrix entry material [43]. Next, use 3D models to optimize layouts is locations and sizes such as setting the thickness of the optimization area, labeling the color of the area to represent the density of the material and considering the long-distance use of the material [44].

In general, materials are based on the availability and proximity of the destination to reduce the time of transport apart from the constraints where the yard depend on the type of material and their characteristics such as compatibility constraints (only the same type of material can be arranged in one area of material) and also consider the security [45]. The problematic study of the unsuitable layout affects the material traffic production and performs the re-layout procedure which consists of three steps is analyzing the existing layout, designing the layout based on SLP (Systematic Layout Planning) and evaluation and alternative selection layout using the 'Simulation Pro Version 6' model [46]. The input data required by the SLP in the study is the product (type of material), the quantity (number/ component produced), the route (operation instructions for each material), services (support services such as monitoring stations and others) and time (type of material was produced at the time). It shows that materials are stored according to the categories of materials which are the shape and density of the material [47].

\subsubsection{Optimizing material flows}

Material control and site layout controls where the "Move Cap Plan" model has been developed to help model the movements of the on-site materials, capture the actual layout and location of the materials and plan the storage and recovery of materials throughout the site during construction as well as integrate the "Move Plan" model to help make arrangements that suit the schedule of activities with the CAPSYTM surveying station that helps to identify the material position [48]. Then, some materials move rapidly that they may be required for the production of a few days after their arrival while the remaining material stays up to 6 months in the storage store and therefore moving and slow-moving materials should be kept in different order [49]. Sampling of materials is one of the activities that requires the loading and unloading process of each bag, drum, or large bag taken from its location where the re-capture of these materials is accompanied by the handling, transport, and transfer of other materials alongside the system storage provisions by class can be used to store patterns of recruitment of the same materials in the same order. 
A good layout planning strategy can produce high productivity in the storage of materials where the layout of the construction projects varies according to site conditions, size of site, storage space, project size and several other factors. The method is definitely reviewed by the previous construction projects, but the planned layout was reflecting the high-risk storage of material which is known as one of the impacts of site congestion is the lack of space. Hence, the limited space is used as storage but the layout is also limited to the material needed in a short period of time and not too long to allow the outgoing material in the storage area to be well designed and proactive.

\subsection{The role of responsible parties}

\subsubsection{Contractor}

The contractor considers the difference between the date and time the material was requested and the ordered was made where the material was delivered, then material management was the key to the project management [4]. Additionally, assigning a task to employees on a timely basis to carry out these tasks is inadequate, but instructions need to be clear, specific the works, monitor workers in their efforts and others. [12].

Review of contractors should choose and obtain appropriate building materials so they can meet contract specifications unless certain brands and model numbers are stated and recommended [20]. This is because the quality and specifications of the building will facilitate storage management where in the event of failure due to inappropriate material code will result in storage area obtaining waste material and take time to remove it. Additionally, contractors need to implement more computer and electronic based businesses ('e-business') through the Internet in managing materials at the construction sites [23]. Subcontractors should perform their activities in parallel and closely with each other which increases competition for site sources such as storage space, building elevators and delivery area $[50]$.

\subsubsection{Suppliers}

Supplier should bring the participation in the design stage with the aim of selecting the appropriate material, the appropriate plan summary to enable the benefits of pricing be given preferential and better payment arrangements. The major responsibilities of manufacturers, suppliers and sales include knowing the materials laws from major manufacturers, project logistics plans as part of suppliers and sales, using third-party logistics and existing technologies from other manufacturing industries, manufacturers, suppliers and sales to determine cost allocation through the company's pricing strategy as well as manufacturers, suppliers, vendors and contractors must be experienced in project success [5].

Supplier also recognizes the difficulties faced and agrees with effective management and information transfer, experienced and well-trained staff, enhancing approaches to avoid issues arising. Additionally, suppliers need to take into account the lack of storage or space around urban areas and limited construction sites. Location management must be proactive in managing the area to accommodate the delivery of materials to the site. This also indicates that suppliers need to comply with delivery schedules and time distribution agreements with various contractors, assisting management processes in a proactive place to reduce or eliminate issues from emerging [8]. Improving productivity in orders and 
quotes, contractors and suppliers can transform conventional activities into more innovative tools and techniques [23]. However, foreign suppliers are seen to provide poor service quality on labeling and packaging [50].

\subsubsection{Material manager}

Material flow from starting material ordered, received, and stored until it is used for use is the basic responsibility of material handling [4]. Material managers should maintain reports such as ordering materials between two dates, material assignments, waste management when purchasing building materials, managing materials up to the location and purchasing orders [51]. The management should increase their surveillance at the site so that the material can be adequately handled when delivered, make sure the material handling process is safely and more awareness of the knowledge of material management, especially in construction sites [12]. The main role of the material manager is to ensure the free flow of materials in the manufacturing sector where it can be achieved through proper production planning, procurement, storage and distribution control [11].

However, it is a common belief that the responsibility of the material manager should include collaboration with the designer on the specification of the material component, purchasing the right material to assist the changing of supply source location, inbound traffic, acceptance and inspection, supplier quality control, inventory control and material control. On larger build sites, material managers should be assisted by suppliers [16].

\subsubsection{Material Surveyors / Engineers / Architects}

This function comes immediately with a product design prepared by the Architect or Engineer and Quantity Surveyor to list all the materials required to execute the project by compiling the material bill with the published construction schedule, the buyer may set up material requirements whenever necessary [16].

Figure 2 shows the framework of storing efficient material storage management at a congested site. The built-in framework is based on the inputs obtained from the previous study in which the ideas are combined and form four essential elements in a material storage management, especially on a congested site. 


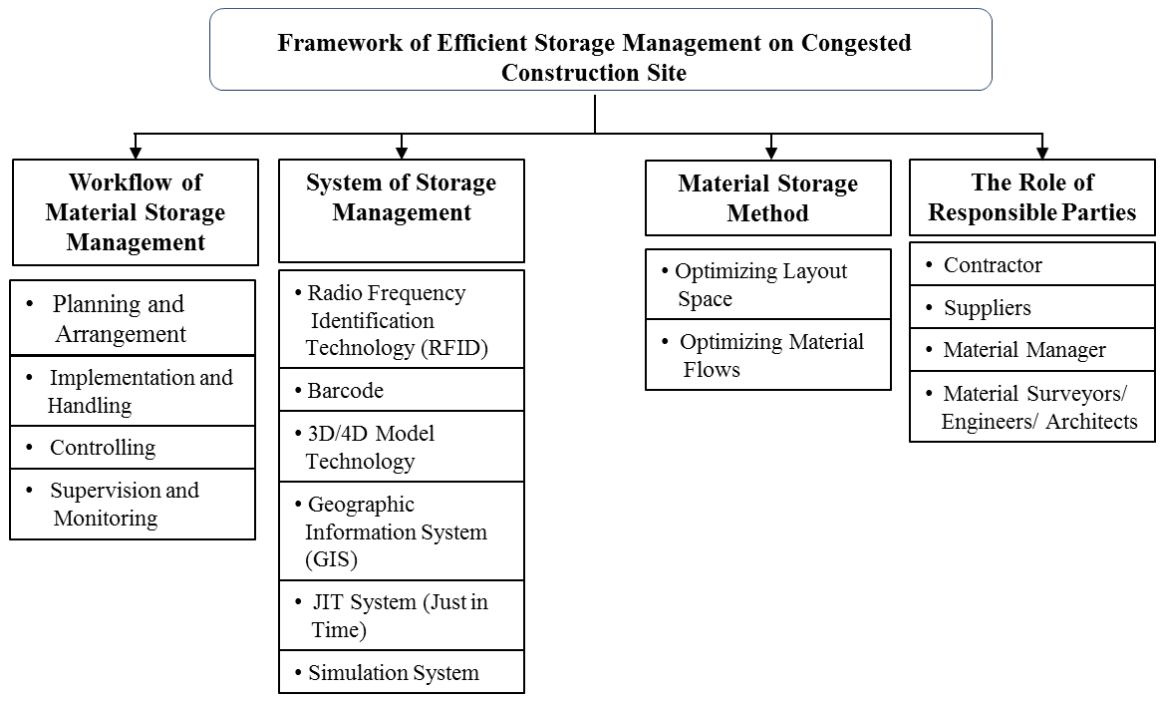

Fig. 2. Framework of efficient storage management

\section{Conclusion}

Congested sites may have a negative impact on storage of materials such as restricted site space to the source of storage space is also limited, site productivity is weak, construction site security is also affected and irregular management system. However, the problem of congestion in a busy urban area of construction is inevitable. Therefore, these problems need to be addressed so as not to affect a high percentage of material storage management work. Additionally, the use of systematic management and layout systems can reduce the congestion of construction sites in limited urban areas.

In conclusion, the first efficient material storage management strategy is view of a congested site where some of its features are limited space, poor site productivity, impaired site security and irregular systems. Then, the strategy to look at the solution of how storage of building materials can be consolidated if a congested site is a combination of elements of the building materials storage management framework. Several types of systems that have been used by past construction projects are references but the possibility of a combination of two or three types of systems can result in higher quality in which each system has the advantages and disadvantages that have been discussed and its suitability to the storage of materials storage the buildup as well as the material storage method is closely related. However, the management workflow is a guide to the work process that will be carried out by the responsible party.

\section{References}

1. A. Almohsen and J. Ruwanpura, "Logistics Management in the Construction Industry," Cib W78-W102 10, (2011)

2. N. Kasim, A. Shamsuddin, R. Zainal, and N. C. Kamarudin, "Implementation of RFID technology for real-time materials tracking process in construction projects," CHUSER 2012 - 2012 IEEE Colloq. Humanit. Sci. Eng. Res., no. Chuser 699-703 (2012) 
3. D. Gedam, "Automation in Material Management System- Critical Review," Int. J. Res. Eng. Sci. Technol. 1, 354-358 (2001)

4. A. A. ; S. . S. Pande, "Study of Material Management Techniques on Construction Project," Int. J. Inf. Futur. Res. 2, 3479-3486 (2015)

5. C. Duiyong, J. Shidong, and S. Mingshan, "Engineering Construction Project Site Logistics Management," J. Chem. Pharm. Res. 6, 353-360 (2014)

6. S. H. Mastor, "Pemahaman serta Kesediaan dalam Mengaplikasikan Sistem Just In Time (JIT) dalam Pengurusan Bahan Binaan di Kalangan Pembekal Bahan-Bahan di Johor Bahru, Johor,” Tesis Ijazah Sarjana(Sains) Pengur. Proj. (2003)

7. J. Spillane, L. Oyedele, J. Meding, A. Konanahalli, B. Jaiyeoba, and I. Tijani, "Challenges of UK/Irish Contractors Regarding Material Management and Logistics in Confined Site Construction," Int. J. Constr. Supply Chain Manag. 1, 25-42 (2011)

8. J. Spillane and L. O. Oyedele, "Strategies for Effective Management of Health and Safety in Confined Site Construction," Constr. Econ. Build. 13, 50-64 (2013)

9. M. M. Mortaheb, J. Y. Ruwanpura, R. Dehghan, and F. Khoramshahi, "Major Factors Influencing Construction Productivity in Industrial Congested Sites," CSCE 2007 Annu. Gen. Meet. Conf. 1111-1120 (2007)

10. S. R. Liwan, "The Framework of Improving on-Site Materials Tracking for Inventory Management Process in Construction Projects," A Thesis degree Master Technol. Manag. 180 (2015)

11. I. . Brutus and O. Chiyem, "Assessment of Material Management and Profitability of an Organization,” J. Policy Dev. Stud. 9, 153-165 (2015)

12. B. T. Arijeloye and F. O. Akinradewo, "Assessment of Materials Management on Building Projects in Ondo State, Nigeria," WSN World Sci. News 55, 168-185 (2016)

13. E. E. Ogbadu, "Profitability Through Effective Management of Materials," $J$. Econ. Int. Financ. 1, 99-105 (2009)

14. P. Alanjari, S. Razavialavi, and S. Abourizk, "A Simulation-based Approach for Material Yard Laydown Planning," Autom. Constr. 40, 1-8 (2014)

15. X. Song, J. Xu, C. Shen, and F. Peña-Mora, "Conflict Resolution-Motivated Strategy Towards Integrated Construction Site Layout and Material Logistics Planning: A bi-Stakeholder Perspective," Autom. Constr. 87, 138-157 (2018)

16. K. A. Okorocha, "Factors Affecting Effective Materials Management in bUILDING Construction Projects- A Case Study of Selected Building Sites, in IMO State, Nigeria," Int. J. Manag. Sci. Bus. Res. 2, 50-59 (2004)

17. S. Donyavi and R. Flanagan, "the Impact of Effective Material Management on Construction Site Performance for Small and Medium Sized Construction Enterprises," Dainty, A.R.J. Procs 25th Annu. ARCOM Conf. 11-20 (2009)

18. U.S Department of Labor, "Material Handling and Storage," OSHA 2236 1-35 (2002)

19. N. Ahzahar, N. A. Karim, S. H. Hassan, and J. Eman, "A study of Contribution Factors to Building Failures and Defects in Construction Industry," Procedia Eng. 20, 249-255 (2011)

20. Z. Ahmed, "The Impact of Material Management On Construction Project Delivery in Maldives," A Thesis Mster Proj. Manag. 104 (2017)

21. K. V. Patel and C. M. Vyas, "Construction Material Management," Natl. Conf. Recent Trends Eng. Technol. (2011)

22. H. Said and K. El-Rayes, "Optimal Material Logistics Planning in Congested Construction Sites," Constr. Res. Congr. 1580-1589 (2012)

23. N. Kasim, S. R. Liwan, A. Shamsuddin, R. Zainal, and N. C. Kamaruddin, 
"Improving on-Site Materials Tracking for Inventory Management in Construction Projects," Proc. Int. Conf. Technol. Manag. , Bus. Entrep. (2012)

24. N. N. Dawood, "Materials Management Systems for the Construction Industry," CIß TG 16, Sustain. Conslruclion 735-743 (1994)

25. A. M. Shaari and N. S. M. Nor, "Position and Orientation Detection of Stored Object Using RFID Tags,” Procedia Eng. 184, 708-715 (2017)

26. M. Skibniewski, "Research Trends in Information Technology Applications in Construction Safety Engineering and Management," Front. Eng. Manag. 1, 246259 (2014)

27. W. Lu, G. Q. Huang, and H. Li, "Scenarios for Applying RFID Technology in Construction Project Management," Autom. Constr. 20, 101-106 (2011)

28. H. Li, Z. Chen, L. Yong, and S. C. W. Kong, "Application of Integrated GPS and GIS Technology for Reducing Construction Waste and Improving Construction Efficiency," Autom. Constr. 14, 323-331 (2005)

29. J. Neese, P. Assistant, K. Snodgrass, and P. Leader, "Bar-Code Tracking Systems Overview," Technol. Dev. Progr. 1-8 (2002)

30. T. Horenburg, J. Wimmer, S. Kessler, and W. A. Günthner, "3D-Planning of Construction Site Equipment based on Process Simulation," Proc. 13th Int. Conf. Comput. Civ. Build. Eng. (2010)

31. S. Gore, L. Song, and N. Eldin, "Photo-Modeling for Construction Site Space Planning," (2017)

32. J. Teizer, "3D Range Imaging Camera Sensing for Active Safety in Construction," J. Inf. Technol. Constr. 13, 103-117 (2008)

33. K. W. Chau, A. M., and J. P. Zhang, "Four-Dimensional Visualization of Construction Scheduling and Site Utilization," J. Constr. Eng. Manag. 130, 598606 (2004)

34. G. H. Watson, R. L. Tucker, J. K. Walters, K. Varghesea, and J. T. O 'connor, "Automated Access Planning On Construction Sites: An Expert GIS Approach," Autom. Robot. Constr. 325-332 (1993)

35. M. H. S. et Al., "Potential Application of GIS to Layout of Construction Temporary Facilities," Int. J. Civ. Eng. 6, 235-245 (2008)

36. V. Kumar, "JIT Based Quality Management: Concepts and Implications in Indian Context," Int. J. Eng. Sci. Technol. 2, 40-50 (2010)

37. I. A. Ocheoha and O. Moselhi, "Impact of Building Information Modeling on JustIn-Time Material Delivery," ISARC 2013 - 30th Int. Symp. Autom. Robot. Constr. Mining, Held Conjunction with 23rd World Min. Congr. 793-801 (2013)

38. Y. Tedla and D. Patel, "Improving Effective Material Management by Identifying common Factors in Building Construction Project," Int. Res. J. Eng. Technol. 5, 146-150 (2018)

39. J. Bong Chunn Tat, "Factors affecting in the preparation of construction work schedule," Thesis degree Master Sci. (2009)

40. Z. M. Jusoh and N. Kasim, "Influential Factors Affecting Materials Management in Construction Projects," Manag. Prod. Eng. Rev. 8, 82-90 (2017)

41. S. Razavialavi and S. AbouRizk, "Simulation Applications in Construction Site Layout Planning," Proc. 30th Int. Symp. Autom. Robot. Constr. Min. 3, 275-284 (2013)

42. M. Park, Y. Yang, H.-S. Lee, S. Han, and S. Ji, "Floor-Level Construction Material Layout Planning Model Considering Actual Travel Path," J. Constr. Eng. Manag. 138, 905-915 (2012)

43. S. Bauer and R. Lackner, "Gradient-Based Adaptive Discontinuity Layout Optimization for The Prediction of Strength Properties in Matrix-Inclusion 
Materials," Int. J. Solids Struct. 63, 82-98 (2015)

44. Z. Liu, S. Cho, A. Takezawa, X. Zhang, and M. Kitamura, "Two-stage LayoutSize Optimization Method for Prow Stiffeners," Int. J. Nav. Archit. Ocean Eng. 18 (2018)

45. P. Alanjari, S. RazaviAlavi, and S. AbouRizk, "Materials and Facility Layout Planning in Construction Projects Using Simulation," Proc. 2014 Winter Simul. Conf. 1469-1480 (2014)

46. D. Suhardini, W. Septiani, and S. Fauziah, "Design and Simulation Plant Layout Using Systematic Layout Planning," IOP Conf. Ser. Mater. Sci. Eng. 277, 1-8 (2017)

47. D. Bäck and P. Johansson, "A Model for Effective Development of Plant Layouts and Material Handling Systems," 67 (2006)

48. I. Tommelein, "Materials Handling and Site Layout Control," Autom. Robot. Constr. 297-304 (1994)

49. D. A. Hailemariam, "Redesign of the Layout and the Materials Flow of a Production Plant," A Master Thesis Conduct. Prod. Plant Moxba-Metrex (2010)

50. M. Hansson and N. Hedberg, "Construction Logistics from A Subcontractor Perspective A case Study of A Congested Construction Site," Master Sci. Thesis Des. Constr. Proj. Manag. Program. (2015)

51. A. R. Patil and S. V Pataskar, "Analyzing Material Management Techniques on Construction Project," Int. J. Eng. Innov. Technol. 3, 96-100 (2013) 